\title{
GESTORES ESCOLARES DA REDE PÚBLICA EM MINAS GERAIS: FATORES DE SATISFAC̣ÃO NO TRABALHO
}

\author{
Luiza Lúcia e Silva Santana* \\ Nina Rosa da Silveira Cunha** \\ Marco Aurélio Marques Ferreira*** \\ Luiz Rodrigo Cunha Moura**** \\ Adriel Rodrigues de Oliveira*****
}

RESUMO: O objetivo deste trabalho foi investigar a presença ou ausência de satisfação no trabalho dos diretores/gestores da educação básica pública, bem como sua interferência na gestão escolar. Tomou-se como referencial as categorias de Qualidade de Vida no Trabalho sugeridas por Walton. A pesquisa é descritiva, numa abordagem quali-quantitativa, usando um questionário semiestruturado. A amostra consistiu de 124 casos distribuídos em 52 cidades de Minas Gerais. Os resultados indicam que há sentimento de satisfação por parte dos diretores/gestores com relação aos fatores relevância do trabalho, integração social na organização, uso e desenvolvimento de capacidades, constitucionalismo e oportunidade de crescimento profissional, o que propicia interferência considerada positiva na gestão escolar. Todavia, existe um sentimento de ausência de satisfação com relação aos fatores associados à remuneração; e um sentimento de indiferença, considerando os fatores associados às condições de trabalho e ao equilíbrio trabalho e vida.

Palavras-chave: Satisfação e Qualidade de Vida no Trabalho. Gestores Públicos. Programa Nacional Escola de Gestores da Educação Básica Pública.

\footnotetext{
* Mestre em Administração pela Universidade Federal de Viçosa (UFV) e Coordenadora Pedagógica do Colégio de Aplicação da Universidade Federal de Viçosa (UFV). E-mail: Ilsilva@ufv.br

* * Doutora em Economia Rural pela Universidade Federal de Viçosa (UFV) e Professora Associada III do Departamento de Administração da Universidade Federal de Viçosa (UFV). E-mail: ninarosa@ufv.br

** * Doutor em Economia Aplicada pela Universidade Federal de Viçosa (UFV) e Professor Adjunto III do Departamento de Administração da Universidade Federal de Viçosa (UFV). E-mail: marcoaurelio@ufv.br

**** Doutor em Administração pela Universidade Federal de Minas Gerais (UFMG) e Professor Adjunto do Centro Universitário UNA. E-mail luizrcmoura@gmail.com

***** Doutor em Administração pela Universidade de São Paulo (USP) e Professor Associado do Departamento de Administração da Universidade Federal de Viçosa (UFV). E-mail: aroli@ufv.br
} 


\section{STATE SCHOOL MANAGERS IN MINAS GERAIS: FACTORS RELATING TO JOB SATISFACTION}

ABSTRACT: The objective of this study was to investigate the presence or absence of satisfaction at work of the directors/managers of basic state/public education, as well as its influence on school management. The category suggestions made by Walton in his "Quality of Work life", were referred to. This research is descriptive, with a qualitative and quantitative approach, using a semi-structured questionnaire. The sample consisted of 124 cases distributed across 52 municipalities of MG. The results indicate that there is a sense of satisfaction on the part of directors / managers with regard to the relevance of their work. Social integration in the organization, use of (and development of) employees' capacities, constitutionalism and opportunities for professional growth, all provide proof of their positive influence on school management. However, there is a feeling of dissatisfaction with respect to factors associated with remuneration (salary), and a feeling of indifference regarding working conditions (and their associated factors) and concerning the work-life/home-life balance.

Keywords: Satisfaction and Quality of Work Life. Directors and Managers of State Education. The National School Program of State Management of Basic Education.

\section{Introdução}

Este artigo investiga a satisfação dos diretores/gestores participantes do Programa Nacional Escola de Gestores da Educação Básica do Ministério da Educação, em Minas Gerais (PN-EGEBP-MEC-MG), relacionada aos fatores pertinentes à qualidade de vida no trabalho, bem como descreve a interferência desses fatores na gestão escolar. Não se atém, portanto, à abordagem e à discussão da realidade escolar e sua gestão no que tange aos fatores relacionados ao trabalho pedagógico. Com origens na teoria da administração, é um estudo diferenciado daqueles usualmente tratados e publicados no âmbito acadêmico da educação. Tem como sujeitos de pesquisa diretores/gestores da rede pública municipal de educação de Minas Gerais. Registra-se que é resultado de pesquisa desenvolvida em programa de pós-graduação strito sensu em Administração, com ênfase em Administração Pública, a qual delineia um cenário de agentes sociais da área educacional.

A busca por novas formas de gerir organizações é preocupação constante, principalmente no que tange à participação das pessoas no desenvolvimento de seu trabalho, visando ao alcance de objetivos comuns. Assim novas demandas emergem das pessoas que se tornam gra- 
dativamente mais instruídas e críticas frente a organizações que muitas vezes oferecem condições de trabalho inadequadas e não satisfatórias.

No campo educacional, essa realidade também é percebida, porém de forma diferenciada. Na concepção de Mintzberg (1995), a escola é classificada como organização profissional em que prevalece um modelo de estrutura burocrática direcionada para a padronização das habilidades das pessoas e não dos processos de trabalho para sua coordenação. Para ele, essa estrutura permite especialistas treinados e, assim, os profissionais atuam de forma independente uns dos outros, mas têm um cliente comum - os alunos.

Dornbush et al. (1996) ratificam essa classificação da escola como partícipe de modelo burocrático, destacando aspectos como o controle burocrático do trabalho docente, a supervisão exercida pelos órgãos governamentais, a avaliação dos conteúdos trabalhados com os alunos e a predominância da institucionalização em prejuízo da formação técnica.

Pensando-se na escola como uma organização que, permanentemente, é cobrada da sociedade e que é responsável pela instrução formal do cidadão, há a necessidade de refletir sobre a questão: Qual a percepção dos dirigentes sobre a presença ou ausência de satisfação relacionada aos fatores intervenientes no contexto de trabalho? Qual a interferência desses fatores na gestão escolar dos participantes do PN-EGEBP-MG?

Os participantes, diretores/gestores, são aqueles profissionais do magistério, portadores do grau de licenciatura plena, indicados ou não por intermédio do voto pela comunidade escolar, nomeados para o exercício do cargo de direção, com atribuições de organizar, coordenar, controlar e avaliar os trabalhos acadêmicos, pedagógicos, administrativos e financeiros.

Dimenstein (2009), comentando sobre a escola pública, registra que nela as salas são superlotadas, os laboratórios não funcionam, os pais se envolvem pouco na educação dos filhos, cujo repertório cultural é, geralmente, baixo. $\mathrm{O}$ autor afirma que existem as mais variadas formas de violência - do xingamento às agressões físicas. Logo, o professor terá uma doença ou desequilibro emocional. Entende-se que esse cenário precisa ser alterado e, necessariamente, a educação tem de se fazer com qualidade. Isso só se concretizará com profissionais satisfeitos e motivados.

O envolvimento das pessoas com o trabalho que se realiza é de extrema importância. No caso da educação, para Critelli (2006, p. 2), “(...) 
esse aspecto, esquecido pela moderna administração, provoca um distanciamento, uma desvinculação das pessoas de seu trabalho...". Pode-se depreender que isso pode gerar ações ineficientes e pouco produtivas junto à sociedade se não houver atenção para esse aspecto.

Nesse sentido, percebe-se a complexidade do tema. Sá et al. (2007) advogam que, embora a qualidade de vida no contexto do trabalho tenha recebido atenção de estudiosos, ainda existem dúvidas e incertezas em relação a seu sentido exato. Assinalam que, no entanto, "praticamente todas as definições guardam entre si um ponto em comum: seu objetivo de propiciar uma maior humanização do trabalho. Ele envolve aspectos psicossociais, satisfação, condições de trabalho, estilos de liderança e higiene, dentre outros".

O tema foi pesquisado por vários estudiosos, abordando aspectos diferenciados (MACHADO, 2002; MELLO, 2006; CUNHA, et al. 2008; WALTON, 1973; WESTLEY, 1979; OLIVEIRA, 2001; HACHMAN, OLDHAM, 1975).

Pautando-se nesse entendimento e considerando a escassez de literatura específica sobre condições de trabalho de diretores/gestores escolares públicos, este estudo se torna de relevância significativa e de caráter original. Por tratar-se de tema relativamente novo, notadamente quando comparado a outras áreas de demandas sociais como saúde, segurança e transportes, responsáveis pelo bem-estar da sociedade, pesquisar a realidade do diretor/gestor escolar na perspectiva de suas condições de trabalho torna-se uma exigência e uma necessidade, visto que constituem parte fundamental da estrutura do processo educacional.

Considerando que a condução do processo educacional, base para alavancar a formação de todas as demais categorias profissionais e na constituição do cidadão pleno, é responsabilidade inerente ao diretor/gestor escolar, principalmente na esfera pública, conhecer sua realidade de trabalho possibilita gerar uma base sistematizada de conhecimentos, agregando contribuições a outros estudos e fornecendo subsídios para a administração pública, com repercussões práticas e organizacionais. Há ainda que se considerar que a educação é componente estratégico para garantir o crescimento econômico do país, promovendo melhoria da distribuição de renda com consequente redução das desigualdades sociais.

Nesse sentido, acredita-se que os resultados deste estudo poderão possibilitar reflexões sobre as condições de trabalho dos 
diretores/gestores das escolas públicas em Minas Gerais. Ainda, espera-se também contribuir favoravelmente para o desenvolvimento das atividades administrativas com repercussão nas acadêmicas.

\section{Referencial teórico}

O trabalho, para algumas pessoas, só tem sentido se tem um significado, uma razão ou um objetivo. Para outras ele é fonte de sentido para a vida, na medida em que, por sua natureza, é ele que garante a sobrevivência. Na esfera educacional, o produto gerado pelo trabalho é a constante construção do conhecimento para a formação do homem, podendo-se depreender que o sentido do trabalho é subjetivo, considerando que vem do âmago individual e que reflete a vivência de cada um em sociedade. É dinâmico e sempre em processo de mudança, visto que é calcado nas motivações e nos interesses particulares que, dependendo da situação, geram ou não satisfação. A satisfação no trabalho, na perspectiva das organizações, é elemento determinante e, assim, faz-se importante ser entendida e trabalhada para se tentar coibir problemas potenciais de insatisfação que possam influenciar a vida organizacional.

Veloso et al. (2005) consideram Herzberg, McGregor e Maslow referências nos estudos sobre motivação e satisfação no trabalho, e Cunha et al. (2008) consideram Walton referência em qualidade de vida no trabalho.

Compreende-se, pois, que o estudo da satisfação no trabalho relacionada aos fatores no contexto de trabalho é fundamental para descrever a interferência dos mesmos na gestão escolar. A teoria de Herzberg e o Modelo de Walton trazem elementos que contribuem com a fundamentação dessa perspectiva.

\subsection{Teoria das Satisfações Humanas}

A Teoria das Satisfações Humanas ou Teoria HigieneMotivacional foi proposta por Frederick Herzberg. Em 1959, ele realizou um trabalho voltado para o mapeamento dos fatores de satisfação e insatisfação no trabalho. Suas descobertas mostraram que os principais fato- 
res de satisfação no trabalho são: o trabalho em si mesmo; a realização sucesso na realização do trabalho; a responsabilidade - autonomia na realização do trabalho; o reconhecimento - ser reconhecido pela tarefa bemexecutada; e a promoção - crescimento profissional.

Herzberg (1967) observou que os principais fatores de satisfação advêm do próprio trabalho e, assim, o trabalho em si é o principal fator de satisfação e que os fatores envolvidos na geração da satisfação e da motivação são independentes e distintos dos fatores que levam à insatisfação no trabalho.

Por outro lado, foram mapeados fatores de insatisfação, quais sejam: política da organização, administração geral da organização, estilo de supervisão, relações interpessoais, condições de trabalho, salário e segurança. Esses fatores de insatisfação raramente são observados como fatores de satisfação e muitos desses fatores de insatisfação relacionam-se ao ambiente de trabalho. O fator salário é observado tanto como de satisfação quanto de insatisfação, predominantemente, porém como de insatisfação.

Suas pesquisas permitiram depreender que um conjunto de fatores propicia satisfação no trabalho e que outro atua como inibidor de satisfação. Os primeiros, fatores de satisfação, estavam vinculados ao trabalho em si e à possibilidade de crescimento pessoal. Os outros, fatores de insatisfação, vinculavam-se ao contexto e às condições de trabalho.

Herzberg (1967, p. 61) concluiu que "o oposto de satisfação no trabalho não é insatisfação, mas sim nenhuma satisfação no trabalho; e da mesma forma, o oposto de insatisfação no trabalho não é satisfação, mas sim nenhuma insatisfação no trabalho". Assim, sua teoria tornou-se conhecida como a teoria dos dois fatores ou teoria do fator dual - Fatores Higiênicos e Motivadores. Para ele o enunciado desse conceito configurase como um problema léxico, uma vez que a satisfação e a insatisfação, frequentemente, são consideradas como ideias antagônicas ou antônimas - o que não é satisfatório tem que ser insatisfatório e vice-versa. Entretanto, o autor registra que quando se trata de entender o comportamento das pessoas no trabalho, muito mais se está presente do que uma combinação de expressões ou palavras, visto que estão presentes duas necessidades do homem: uma que pode ser entendida como originária da sua própria natureza e a outra que está relacionada a uma forma ou característica desse homem agir, cada um de um jeito, de forma singular. 
Em sua pesquisa, indagou às pessoas que fatores presentes no trabalho delas lhes proporcionavam extrema satisfação ou extrema insatisfação. Diante dos resultados ele constatou que aqueles que provocaram extrema satisfação foram: realização, reconhecimento, o próprio trabalho, responsabilidade, progresso e crescimento. Por outro lado, aqueles que provocaram extrema insatisfação foram: política e administração da empresa, supervisão, relações com o supervisor, condições de trabalho, salário, relacionamento com os colegas, vida pessoal, relações com subordinados, status e segurança.

Considerando os fatores higiênicos e motivadores de Herzberg, pode-se depreender que fatores higiênicos são aqueles que procuram satisfazer as necessidades fisiológicas, de segurança e sociais. Os fatores motivadores são aqueles que procuram satisfazer as necessidades de estima e autorrealização. Para Herzberg a única maneira de fazer com que o trabalhador sinta vontade de realizar a tarefa é proporcionando-lhe satisfação no trabalho. Ou melhor, a motivação acontecerá somente a partir dos fatores motivadores. O caminho apontado por ele para a motivação é o enriquecimento da tarefa.

A inexistência de relação direta entre satisfação no trabalho e produtividade foi a conclusão das pesquisas de Herzberg. Concomitantemente, constatou-se a existência de relação entre satisfação no trabalho, rotatividade e absenteísmo. $\mathrm{O}$ autor registra que a separação entre os fatores higiênicos e motivacionais não é absoluta. Para ele a análise do grupo estudado, considerando-se uma escala, é que indicará que pode haver fatores com uma tendência a se apresentarem como higiênicos e outros com tendência a serem motivacionais.

\subsection{Qualidade de vida no trabalho}

O entendimento de Qualidade de Vida no Trabalho (QVT) vai além dos aspectos legislativos ou de planos de benefícios. Relaciona-se com a experiência emocional da pessoa com o seu trabalho, refletindo sobre o seu bem-estar.

As principais abordagens teóricas de QVT passam por vários estudiosos, começando por Louis Davis (1966), que, ao configurar o desenho do cargo, atentou para os aspectos de bem-estar e saúde de seus ocu- 
pantes. A partir de então várias abordagens foram desenvolvidas (WALTON, 1973; WESTLEY, 1979; BELANGER, 1973; THÉRIAULT, 1980; DENIS, 1980; WERTHER E DAVIS, 1983; NADLER E LAWLER, 1983; HUSE E CUMMINGS, 1985), conforme Oliveira (2001).

Entre as abordagens supramencionadas, o destaque fica por conta dos modelos de Nadler e Lawler (1983), Hackman e Oldham (1975) e de Walton (1973).

O modelo de Nadler e Lawler enfatizou as variáveis de participação, remuneração, variedade de habilidades, jornada de trabalho, condições de trabalho, ambiente social e físico de trabalho (OLIVEIRA, 2001). Hackman e Oldham (1975) trabalharam com as dimensões do cargo, que, por sua vez, afetavam as condições psicológicas de seu detentor.

A abordagem de Walton (1973) analisou desde necessidades básicas dos indivíduos, chegando até as condições organizacionais. Afiançava que o nível de satisfação do trabalhador, bem como sua autoestima, era diretamente proporcional à QVT.

\subsection{Walton - Categorias conceituais para QVT}

Walton (1973) considera que a vida profissional de quase todos os trabalhadores pode ter problemas, independentemente da posição deles. Considera que a frustração, o aborrecimento e a raiva podem ser comuns a eles, gerando onerosidade tanto individual quanto organizacional. Diante dessa concepção, reconhece-se quão é difícil e complexa a questão da qualidade de vida no trabalho e acredita-se que ela não é determinada isoladamente por atributos pessoais ou situacionais, mas sim pela interação desses dois fatores: indivíduo-organização.

Em face dessas premissas, sugere que um programa de qualidade de vida no trabalho deve pautar-se no princípio de uma organização mais humana, em que seja engendrado relativo grau de responsabilidade e de autonomia no cargo, feedback sobre o desempenho, cargos com tarefas adequadas e com ênfase no desenvolvimento pessoal do indivíduo. Para tanto, Walton (1973) propôs oito categorias conceituais ou critérios para a construção de uma estrutura que permita analisar Qualidade de Vida no Trabalho: - Compensação justa e adequada - o trabalho é entendido como um meio pelo qual os indivíduos possam ter seu sustento. Refere-se à satisfação 
do empregado quanto à política de remuneração da organização; - Condições de segurança e saúde no trabalho - dizem respeito às esferas ambientais físicas do trabalhador e à jornada de trabalho; - Uso e desenvolvimento de capacidades são as oportunidades que uma organização propicia para que o empregado desenvolva suas habilidades e conhecimentos; - Oportunidade de crescimento continuo e segurança - É a oportunidade do trabalhador de poder crescer na organização; - Integração social na organização - é o estabelecimento de um bom nível de integração social na empresa; - Constitucionalismo na organização do trabalho - são os direitos e deveres dos trabalhadores na organização; Trabalho e o espaço total da vida - refere-se ao equilíbrio entre o trabalho e a vida pessoal do indivíduo; - Relevância social da vida no trabalho - é o respeito que a empresa tem por seus funcionários.

À luz dessas categorias e critérios, acredita-se que, se bem-gerenciados, poder-se-iam obter níveis de satisfação mais desejados e, consequentemente, influenciar positivamente nos níveis de desempenho e produtividade de qualidade. $\mathrm{O}$ oposto, acredita-se, poderia gerar prejuízos humanos e organizacionais, levando a uma perda no trabalho e no produto acabado, induzindo a um declínio da qualidade, absenteísmo, rotação elevada e queda da produtividade.

\section{Referencial do objeto}

\subsection{Programa Nacional Escola de Gestores da Educação Básica do Ministério da Educação (PN-EGEBP-MEC)}

Esse Programa faz parte do conjunto de políticas que vêm sendo desenvolvidas pelo Ministério da Educação, por meio da Secretaria de Educação Básica, objetivando contribuir com a formação efetiva de gestores educacionais da escola pública. Atende em regime de colaboração com os sistemas de ensino, entidades educacionais e universidades. Em Minas Gerais, as IFES parceiras escolhidas foram: Universidade Federal de Minas Gerais (UFMG); Universidade Federal de Uberlândia (UFU); e Universidade Federal de Viçosa (UFV).

A proposta de formação destina-se aos profissionais que integram a equipe gestora da escola: diretor e vice-diretor ou demais cargos 
de gestão pedagógica. A prioridade no atendimento aos profissionais é dada àqueles que atuam em escolas com Índice de Desenvolvimento da Educação Básica - IDEB - abaixo da média nacional e municípios com baixo IDEB.

\subsection{A escola pública}

A escola atual, enquanto instituição formalmente destacada para a transmissão do saber, vem para atender ao constante dinamismo de mudanças e exigências da sociedade, visto que, sob a sua tutela, o saber produzido está jurisdicionado e os profissionais que a compõem têm a função de transmitir esse saber.

Pode-se registrar que a escola pública carrega nuances próprias de condições de trabalho, tem representatividade social, detém um corpo discente diferenciado, possibilita estruturação de carreira para os docentes, sofre pressões por resultados, vivencia desafios e constitui papel de referência, dado que trabalha com a formação dos indivíduos.

Acredita-se que os profissionais da escola pública vivenciam seu dia a dia em conformidade com uma estrutura de funcionamento definida e de acordo com valores e tradições. No que toca ao aspecto estrutural, as escolas são parte das organizações de tipo burocrático, tendo em vista sua maneira de regulação e de poder, em que se verifica a imposição de normas, regulamentos e regras, assim como, na maioria delas, há a imposição de seus dirigentes para um mandato.

\subsection{Diretor Escolar}

Paro (2002) registra que o diretor escolar atua num papel contraditório, uma vez que tem que exercer a função de educador, tendo em vista os objetivos educacionais da escola, e, concomitantemente, administrar a escola nos termos das orientações do sistema de ensino, que, muitas vezes, são de natureza burocrática e confiscam longo tempo de trabalho do diretor, causando, inclusive, a resolução dos problemas cotidianos da unidade escolar, perpassando a estrutural e material, indo até a pessoal. Diante desse cenário, a função de educador desse diretor se relega a um 
plano secundário. Além disso, o diretor também fica exposto a situações diversas, envolvendo os trabalhadores da escola, os discentes e seus pais, com as diferentes reivindicações - de melhores condições de trabalho, de ensino e assistência pedagógica. Ainda, também fica exposto ao poder público nas diversas esferas, uma vez que, como o funcionário, tem que cumprir as orientações superiores (TORRES; GARSKE, 2000).

\section{Metodologia}

\subsection{Procedimentos}

A pesquisa é de cunho descritivo, numa abordagem quali-quantitativa, e quanto aos meios, caracteriza-se como bibliográfica e de campo.

A população pesquisada constituiu-se de um grupo de 327 sujeitos, conseguindo-se uma amostra de 124 casos de diretores/gestores, os quais se encontravam em situação regular com o PN-EGEBP-MEC.

$\mathrm{O}$ instrumento de coleta de dados foi um questionário estruturado em blocos e constituiu-se de questões de múltipla escolha e de questões abertas. A escala do tipo Likert, de 7 pontos, foi adotada, possibilitando aos sujeitos pesquisados indicar o grau de satisfação em cada uma das questões relacionadas às categorias sugeridas por Walton (1973). As questões abertas referiram-se à percepção sobre a interferência dessas categorias na gestão escolar, permitindo proceder, posteriormente, à análise de conteúdo.

O questionário, via e-mail, foi encaminhado aos participantes do PN-EGEBP-MEC-MG, garantindo o sigilo das respostas. À medida que os sujeitos respondiam, em tempo real, os dados iam compondo a planilha com as informações solicitadas. Os dados coletados foram transportados para um arquivo do Statistical Package for Social Sciences - 15.0 SPSS.

A estrutura de análise da pesquisa compreendeu duas frentes: a primeira, tomando como referencial o entendimento de que satisfação é um conceito subjetivo, difícil de ser mensurado e que, em se tratando de sentimento, há que se estabelecer um critério para verificar se ela está presente ou ausente na percepção dos diretores/gestores com relação ao contexto do trabalho, no caso. Assim, a premissa básica foi determinar 
que, mesmo que o entendimento do senso comum sobre o contrário de satisfação seja insatisfação, para fins metodológicos deste estudo, o contrário de satisfação é ausência de satisfação, e o contrário de insatisfação é ausência de insatisfação, conforme conclusão emanada das pesquisas e constante da Teoria das Satisfações Humanas, de Herzberg (1967); e a segunda, tomando como referencial de instrumento as dimensões de QVT, sugeridas por Walton (1973), e adaptadas ao objeto deste estudo fatores de satisfação relacionados ao contexto de trabalho de diretores/gestores.

A estratégia utilizada para a análise dos dados consistiu, inicialmente, em especificar as variáveis relacionadas a cada dimensão, conforme sugerido por Hair et al. (2005). Posteriormente, com o objetivo de verificar a confiabilidade de cada dimensão, foi calculado o alpha de "Cronbach". Feito isso, adotou-se a escala somada com o intuito de combinar os escores individuais em um escore total, único, de modo que ele representasse quantitativamente a dimensão que se deseja avaliar, mediante a soma de todas as afirmações.

Assim foi realizada a Análise Exploratória de Dados (AED) para identificação dos fatores de satisfação, por meio das dimensões definidas anteriormente, oriundas da escala somada e, por fim, a descrição das percepções dos diretores/gestores sobre a interferência desses fatores na gestão escolar, comparando os dados por polos regionais de ensino.

A partir da escala previamente definida para a coleta de dados, sincronizaram-se as médias encontradas em cada uma das categorias de Walton (1973), no intervalo de muito insatisfeito (1) a muito satisfeito (7), aos parâmetros para interpretação discriminados no Quadro 1. Finalmente, a estratégia utilizada para descrever a percepção dos diretores sobre a interferência dos fatores na gestão escolar consistiu em verificar os resultados da AED e, num segundo momento, em análise de conteúdo. Segundo Bardin (1977), a análise de conteúdo é um conjunto de técnicas de análise das comunicações visando a obter, por procedimentos sistemáticos e objetivos de descrição do conteúdo das mensagens, indicadores (quantitativos ou não) que permitam a inferência de conhecimentos relativos às condições de produção/recepção (variáveis inferidas) dessas mensagens. 


\section{QUADRO 1}

Parâmetros para identificação de satisfação

\begin{tabular}{c|c|c} 
Números & Representação & Parâmetros \\
\hline 1 & Muito insatisfeito & \\
2 & Insatisfeito & Ausência de satisfação \\
3 & Puco insatisfeito & \\
\hline 4 & Indiferente & Indiferença \\
\hline 5 & Pouco satisfeito & \\
6 & Satisfeito & Presença de satisfação \\
7 & Muito satisfeito &
\end{tabular}

\subsection{Descrição dos construtos}

Os construtos do modelo de Walton, segundo as categorias, são: Remuneração-Compensação justa e adequada (equidades interna e externa, justiça na compensação); Condições de trabalho (jornada de trabalho, ambiente físico); Uso e desenvolvimento de capacidades (autonomia, qualidades múltiplas, tarefas completas); Oportunidade de crescimento e segurança (possibilidade de carreira, crescimento pessoal, segurança e estabilidade); Integração social na organização (ausência de preconceitos, relacionamento, senso comunitário); Constitucionalismo (direitos trabalhistas, privacidade, liberdade de expressão); Equilíbrio trabalho e vida (equilíbrio entre o trabalho e a vida pessoal); Relevância do trabalho (imagem da empresa, responsabilidade social).

\section{Fatores de satisfação no contexto de trabalho dos diretores/gestores}

À luz dos estudos de Herzberg (1967), esse item objetivou identificar os fatores de satisfação no contexto de trabalho dos participantes.

\subsection{Confiabilidade interna das categorias}

Em todas as categorias estudadas foram consideradas mais de quatro variáveis, as quais apresentaram correlação não-paramétrica positi- 
va (Spearman) entre si ao nível de significância 0,01 e, acima de 0,3 (Hair et al., 2005). Na categoria Condições de trabalho, observou-se que apenas as variáveis condições de integridade física e autonomia da gestão financeira não apresentaram coeficiente de correlação superior a 0,3. Entretanto, considerando a finalidade deste estudo, elas foram mantidas, pois são importantes para a compreensão do objeto investigado. Observados esses procedimentos, passou-se ao cálculo do alpha de "Cronbach" (Tabela 1). Verificou-se que, com exceção da categoria Condições de trabalho, que apresentou valor muito bom, todas as outras apresentaram valor excelente para o alpha de "Cronbach", indicando a confiabilidade interna da escala, assim como a validade para mensurar cada uma das categorias.

Para identificar os fatores de satisfação dos diretores/gestores com relação às categorias de Walton (1973), adotou-se como premissa básica a conclusão de Herzberg (1975), segundo a qual "o oposto de satisfação no trabalho não é insatisfação, mas sim nenhuma satisfação no trabalho; e da mesma forma, o oposto de insatisfação no trabalho não é satisfação, mas sim nenhuma insatisfação no trabalho".

\section{TABELA 1}

Confiabilidade interna das categorias

\begin{tabular}{c|c|c|c} 
Dimensões & Alpha & N. de variáveis & Intensidade da associação \\
\hline Remuneração - Compensação justa e adequada & $\mathbf{0 , 9 1 7}$ & $\mathbf{8}$ & Excelente \\
\hline Condições de trabalho & $\mathbf{0 , 8 9 9}$ & $\mathbf{1 0}$ & Muito boa \\
\hline Uso e desenvolvimento de capacidades & $\mathbf{0 , 9 4 6}$ & $\mathbf{8}$ & Excelente \\
\hline Oportunidade de crescimento e segurança & $\mathbf{0 , 9 0 5}$ & $\mathbf{6}$ & Excelente \\
\hline Integração social na organização & $\mathbf{0 , 9 0 9}$ & $\mathbf{1 1}$ & Excelente \\
\hline Constitucionalismo ou institucionalismo & $\mathbf{0 , 9 2 8}$ & $\mathbf{1 0}$ & Excelente \\
\hline Equilíbrio trabalho e vida & $\mathbf{0 , 9 4 2}$ & $\mathbf{5}$ & Excelente \\
\hline Relevância do trabalho & $\mathbf{0 , 9 1 2}$ & $\mathbf{1 1}$ & Excelente
\end{tabular}

Referente a cada dimensão foram consideradas as variáveis: Remuneração - Compensação justa e adequada (salário, diárias, seguros e assistência hospitalar, e benefícios); Condições de trabalho (carga horária de trabalho, jornada, autonomia, equipamentos, segurança, condições físicas e ambientais, e tecnologia); Uso e desenvolvimento de capacidades (liberdade para planejar, executar, avaliar as ações, acessibilidade a informações e atualização permanente); Oportunidade de crescimento e segurança (possibilidade de ascensão na carreira, como desenvolvimento de 
possibilidades, e possibilidades de aplicar novos conhecimentos); Integração social na organização (relações interpessoais e administrativas, apoio da organização, clima organizacional e cultura organizacional, estilo de supervisão e política da organização, e autonomia na realização do trabalho); Constitucionalismo (direitos na organização, respeito à possibilidade de reivindicações, grau de privacidade e tratamento justo dos superiores, e política da organização); Equilíbrio trabalho e vida (o trabalho em si, o tempo que ele exige e a estabilidade de horários, e preocupações do trabalho refletindo na vida); e, Relevância do trabalho (o trabalho em si, o respeito e a importância atribuídos a ele, e reconhecimento pela tarefa executada, e ter sucesso na realização do trabalho).

\subsection{Análise exploratória dos dados - AED}

Por meio da AED, conforme Tabela 2 e Gráfico 1, à luz dos entendimentos de Herzberg (1967), foram identificados os fatores de satisfação com relação às dimensões de Walton (1973), estabelecendo-se contrapontos entre si.

\section{TABELA 2}

Estatística descritiva e classificação das categorias Fonte: Resultados da pesquisa.

\begin{tabular}{c|c|c|c|c|c} 
Dimensões & Mínimo & Máximo & Média & Mediana & Moda \\
\hline Relevância do trabalho & $\mathbf{3 , 3 6}$ & $\mathbf{7 , 0 0}$ & $\mathbf{5 , 8 9}$ & $\mathbf{6 , 0 9}$ & $\mathbf{6 , 0 9}$ \\
Integração social na organização & $\mathbf{3 , 6 4}$ & $\mathbf{7 , 0 0}$ & $\mathbf{5 , 7 4}$ & $\mathbf{5 , 8 2}$ & $\mathbf{6 , 1 8}$ \\
Uso e desenvolvimento de capacidades & $\mathbf{1 , 0 0}$ & $\mathbf{7 , 0 0}$ & $\mathbf{5 , 3 2}$ & $\mathbf{5 , 5 0}$ & $\mathbf{6 , 0 0}$ \\
Constitucionalismo ou institucionalismo & $\mathbf{1 , 6 0}$ & $\mathbf{7 , 0 0}$ & $\mathbf{5 , 3 1}$ & $\mathbf{5 , 4 0}$ & $\mathbf{5 , 2 0}$ \\
Oportunidade de crescimento e segurança & $\mathbf{1 , 0 0}$ & $\mathbf{7 , 0 0}$ & $\mathbf{5 , 0 2}$ & $\mathbf{5 , 1 7}$ & $\mathbf{6 , 0 0}$ \\
Equilíbrio trabalho e vida & $\mathbf{1 , 0 0}$ & $\mathbf{7 , 0 0}$ & $\mathbf{4 , 4 4}$ & $\mathbf{4 , 6 0}$ & $\mathbf{5 , 0 0}$ \\
Condições de trabalh & $\mathbf{1 , 1 0}$ & $\mathbf{6 , 7 0}$ & $\mathbf{4 , 1 7}$ & $\mathbf{4 , 1 0}$ & $\mathbf{4 , 3 0}$ \\
Remuneração - Compensação justa e adequada & $\mathbf{1 , 0 0}$ & $\mathbf{6 , 2 5}$ & $\mathbf{3 , 1 6}$ & $\mathbf{3 , 1 3}$ & $\mathbf{3 , 1 3}$
\end{tabular}

FONTE: Resultados da pesquisa

As informações constantes da Tabela 2 e do Gráfico 1 levam a depreender que as categorias Relevância do trabalho e Integração social na organização são aquelas que se constituem como fatores de maior presença de satisfação pelos diretores/gestores, de acordo com os valores encontrados nas medidas de tendência central. Ressalta-se que essas informações estão 
de acordo com as constatações de Herzberg (1967) de que os fatores presentes no trabalho das pessoas que proporcionam extrema satisfação são realização, reconhecimento, o próprio trabalho, responsabilidade, progresso e crescimento.

Em contrapartida, a categoria Remuneração - Compensação justa e adequada é aquela que se constitui como fator de ausência de satisfação, fato corroborado pelos baixos valores das medidas de tendência central. Esse resultado remete àquele das pesquisas de Herzberg (1967), o qual constatou que, entre outros, salário é um dos provocadores de extrema insatisfação.

\section{GRÁFICO 1}

Distribuição de frequência das categorias

Fonte: Resultados da pesquisa.

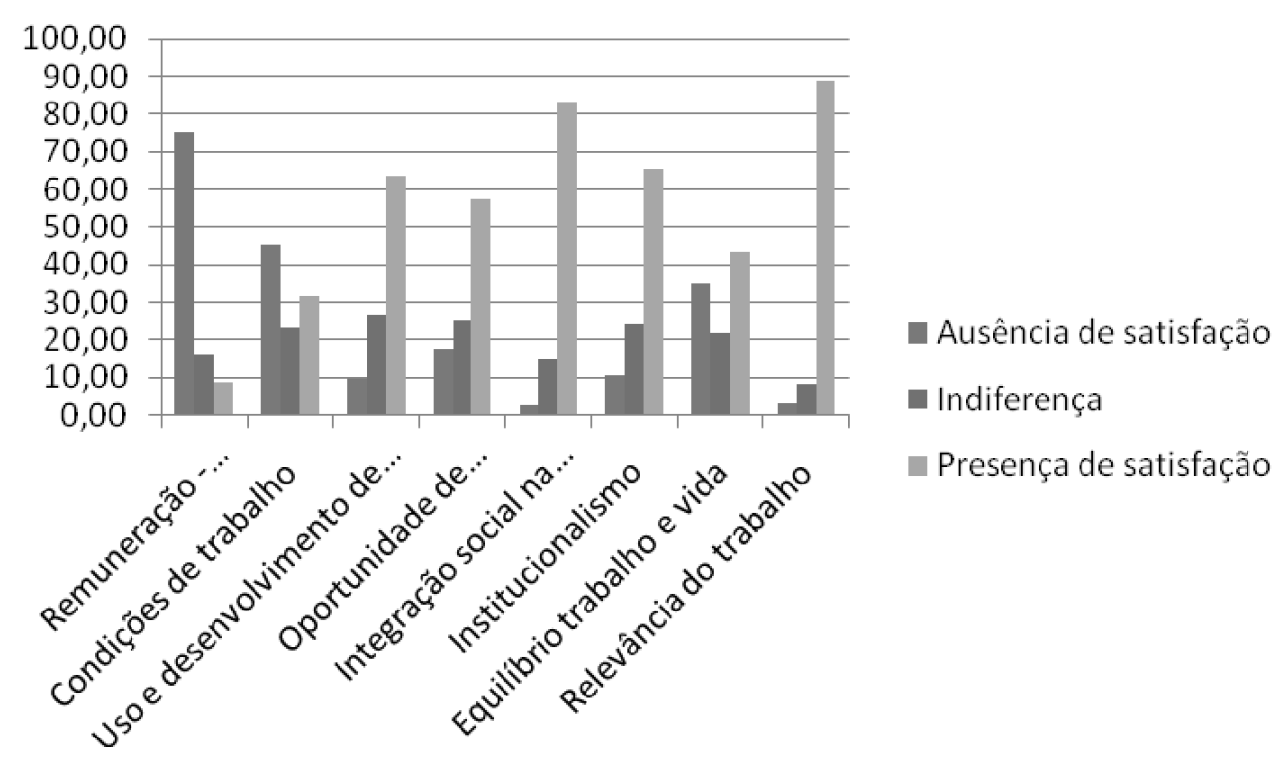

Os diretores/gestores demonstram sentimento de indiferença com relação aos fatores relacionados às dimensões Condições de trabalho e Equilíbrio trabalho e vida, pois os valores encontrados para as medidas de tendência central encontram-se na faixa de classificação como sendo de sentimento de indiferença. 
6. Percepção dos Diretores/Gestores, comparativamente por polos regionais, sobre a interferência de fatores relacionados ao trabalho na gestão escolar

A descrição da percepção da satisfação dos participantes foi realizada por meio da análise de conteúdo. A descrição focou cada categoria, comparativamente, por polos regionais, destacando-se em cada uma os sentimentos dos dirigentes sobre a presença ou ausência de satisfação e a interferência de fatores no contexto do trabalho na gestão escolar, inferindo conteúdo das respostas emanadas pelos sujeitos pesquisados (Tabela 3).

\section{TABELA 3}

Categorias por Polos Regionais de Ensino

Médias por Polos Regionais

\begin{tabular}{c|c|c|c|c|c|c} 
Dimensões & Polo 1 & Polo 2 & Polo 3 & Polo 4 & Polo 5 & Polo 6 \\
\hline Remuneração - Compensação justa e adequada & $\mathbf{3 , 1 8}$ & $\mathbf{2 , 9 6}$ & $\mathbf{2 , 9 6}$ & $\mathbf{4 , 8 8}$ & $\mathbf{3 , 5 2}$ & $\mathbf{3 , 3 8}$ \\
Condições de Trabalho & $\mathbf{4 , 3 3}$ & $\mathbf{3 , 4 0}$ & $\mathbf{3 , 9 6}$ & $\mathbf{4 , 9 0}$ & $\mathbf{4 , 6 7}$ & $\mathbf{4 , 3 6}$ \\
Uso e desenvolvimento de capacidades & $\mathbf{5 , 3 1}$ & $\mathbf{5 , 3 6}$ & $\mathbf{5 , 2 8}$ & $\mathbf{6 , 1 3}$ & $\mathbf{5 , 5 6}$ & $\mathbf{5 , 3 1}$ \\
Oportunidade de crescimento e segurança & $\mathbf{5 , 3 3}$ & $\mathbf{4 , 9 8}$ & $\mathbf{4 , 7 8}$ & $\mathbf{4 , 5 0}$ & $\mathbf{4 , 7 2}$ & $\mathbf{5 , 0 4}$ \\
Integração social na organização & $\mathbf{5 , 8 2}$ & $\mathbf{5 , 7 7}$ & $\mathbf{5 , 6 6}$ & $\mathbf{6 , 9 1}$ & $\mathbf{5 , 7 9}$ & $\mathbf{5 , 7 0}$ \\
Constitucionalismo ou Institucionalismo & $\mathbf{5 , 3 7}$ & $\mathbf{5 , 1 3}$ & $\mathbf{5 , 1 7}$ & $\mathbf{6 , 7 0}$ & $\mathbf{5 , 3 7}$ & $\mathbf{5 , 4 4}$ \\
Equilíbrio trabalho e vida & $\mathbf{4 , 5 2}$ & $\mathbf{3 , 6 3}$ & $\mathbf{4 , 6 5}$ & $\mathbf{6 , 4 0}$ & $\mathbf{3 , 5 7}$ & $\mathbf{4 , 2 9}$ \\
Relevância do trabalho & $\mathbf{6 , 0 1}$ & $\mathbf{5 , 3 6}$ & $\mathbf{5 , 8 9}$ & $\mathbf{6 , 8 2}$ & $\mathbf{5 , 8 0}$ & $\mathbf{5 , 8 0}$
\end{tabular}

Polo 1 = Centro - Belo Horizonte, Polo 2 = Sul - Varginha, Polo 3 = Zona da Mata - Juiz de Fora, Polo 4 = Triângulo - Uberlândia, Polo 5 = Norte $\cdot$ Montes Claros, Polo 6 = Vale do Aço $\cdot$ Governador Valadares

FONTE: Resultados da pesquisa.

Nesse momento, privilegiou-se o entendimento de Walton (1973), o qual considera que a vida profissional de quase todos os trabalhadores pode ter problemas, independentemente da posição ou status dele, e que a qualidade de vida no trabalho é influenciada por atributos pessoais e organizacionais.

\subsection{Remuneração - Compensação Justa e Adequada}

Para Walton (1973), as pessoas trabalham para ter uma forma de se manter, de se sustentar. No entanto, a remuneração do trabalho pode ser um fator inibidor de satisfação. Neste estudo, essa ideia é corrobora- 
da, uma vez que essa questão é fator inibidor de satisfação. Pode-se depreender que o sentimento manifestado pelos diretores, ausência de satisfação com relação à remuneração, interfere na QVT desses sujeitos, assim como pode refletir na gestão da escola em que atuam. Acredita-se que esse reflexo pode ser considerado negativo, na medida em que não há um sentimento de justiça com relação à compensação e não há equilíbrio de salários entre sujeitos congêneres no mercado de trabalho, inibindo iniciativas diversas, diminuindo a dedicação, aumentando a frustração e provocando o sentimento de indignação. Observa-se, pelo registro do sujeito 1, que não há equidade externa. Pode-se depreender, também, que apesar disso, se percebe um sentimento de orgulho pelo significado que a escola tem - é uma referência na cidade.

Uma escola não se faz apenas com o diretor, professores e alunos. É preciso também a participação de toda comunidade, isso graças a Deus nos temos, por isso nossa escola é referência na cidade, como uma escola de qualidade. Porém o salário dos profissionais que aqui atuam é bem desvalorizado. Como pertencemos ao município, nosso salário não acompanha o do Estado. Atualmente uma professora "primária" (que atua na E. Infantil ou E. Fundamental) recebe pouco mais que o salário mínimo, se tiver apenas um cargo. Isso desmotiva e impede de buscar mais conhecimentos específicos. A falta de material bom para trabalho também é um fator preocupante. Nessa profissão temos que usar a criatividade sempre, inclusive, para sobreviver $(\mathrm{D} / \mathrm{G}-1)$.

Observou-se, pelo registro do sujeito 115, que, apesar da ausência de satisfação, do sentimento de indignação, da desmotivação, há um esforço para que isso não interfira na gestão escolar.

$\mathrm{Na}$ minha percepção algumas questões interferem sim, principalmente quando a questão é salarial. Fico indignada até mesmo desmotivada quanto a desvalorização, uma vez que não deixo que esta insatisfação interfira na minha prática quanto gestora $(\mathrm{D} / \mathrm{G}-115)$.

Os Polos Regionais Mata - Juiz de Fora e Sul - Varginha, Centro - Belo Horizonte e Vale do Aço - Governador Valadares são aqueles em que os diretores/gestores manifestaram ausência de satisfação, pois apresentaram médias em torno de 3,00. No Polo Regional Norte - Montes Claros, também há manifestação de ausência de satisfação $(3,52)$, tendendo para um sentimento de indiferença. Já no Polo Regional Triângulo - 
Uberlândia, com a média de maior valor $(4,88)$, verificou-se sentimento de indiferença, com indícios de satisfação (Tabela 3).

\subsection{Condições de trabalho}

Relacionadas às esferas ambientais físicas do trabalhador e à jornada de trabalho, pressupõem a fixação de horários mais justos de trabalho, a garantia de condições físicas seguras e salubres, bem como sugere uma política que favoreça o bem-estar de todos. Foi registrado sentimento de indiferença entre os diretores, interferindo na QVT, refletindo na gestão da escola e sendo considerado negativo, na medida em que não há autonomia de gestão, prevalece a burocracia e faltam condições de trabalho. Observa-se, pelo registro dos sujeitos 10 e 23, a expressão desse sentimento.

Não resta duvida que estes fatores interferem profundamente no dia a dia na atuação do gestor, uma vez que muitas vezes o que emperra um trabalho mais dinâmico é a burocracia do sistema, que em muito dos casos demora se meses para atender uma necessidade pedagógica que deveria ser contemplada em caráter emergencial, por falta de mobilidade financeira ou até mesmo legal. $\mathrm{O}$ maior desafio de um gestor da rede publica municipal é lidar com todos os aspectos burocráticos e ao mesmo tempo ter que administrar os conflitos e o dia a dia da instituição. Sem falar na dificuldade de ter ainda a verba destinada a escola sob o comando da Prefeitura Municipal (D/G-10).

São muitos os fatores que interferem na realização do trabalho de gestor, desde a falta de materiais, indisciplina, licença excessiva de professores e funcionários, falta de compromisso de alunos e família, estrutura física deficitária, violência e tantos outros, que fazem com que o gestor passe o dia "apagando fogo" e o mais importante, que é o pedagógico, fica legado a segundo plano, infelizmente! Mas tentamos fazer a nossa parte da melhor forma possível, pois acreditamos em um futuro melhor para nossas crianças (D/G 23).

Verifica-se que os Polos Regionais Centro - Belo Horizonte e Vale do Aço - Governador Valadares são aqueles em que os diretores/ gestores manifestaram o sentimento de indiferença (4,33 e 4,36, respectivamente). Nos Polos Regionais Triângulo - Uberlândia e Norte - Montes Claros, também há manifestação de indiferença, tendendo para indícios 
de satisfação (4,90 e 4,65, respectivamente). Pode-se observar que, no Polo Sul - Varginha, houve manifestação de ausência de satisfação e, no Polo Mata - Juiz de Fora, tendência ao sentimento de indiferença, média de 3,96 (Tabela 3).

\subsection{Uso e desenvolvimento de capacidades}

Considerou-se que a questão uso e desenvolvimento de capacidades é propiciador de satisfação entre os sujeitos. O sentimento manifestado pelos diretores ratifica a presença de satisfação, permitindo-lhes expressar sentimento de liberdade, de possibilidades de lidar com as exigências do trabalho de forma autônoma. Observa-se, pelo registro do sujeito 123 , a expressão desse sentimento.

Acredito que muitos desses fatores podem interferir no bom andamento da gestão, inclusive no que refere a autonomia do gestor na resolução de problemas e na tomada de decisão. O gestor que não tem autonomia dentro da escola e também junto aos seus superiores não consegue desenvolver um bom trabalho e isso interfere na qualidade de ensino da escola (D/G - 123).

De acordo com a Tabela 3, todos os polos apresentaram presença de satisfação, sendo o Polo Regional Triângulo - Uberlândia aquele em que os diretores/gestores manifestaram esse sentimento de forma mais relevante $(6,13)$.

\subsection{Oportunidade de crescimento e segurança}

Considerou-se que a questão oportunidade de crescimento profissional é fator propiciador de satisfação entre os diretores/gestores. Pode-se depreender que o sentimento manifestado por eles é de satisfação com relação à oportunidade de crescimento profissional. Esse reflexo é positivo, na medida em que há um sentimento de oportunidades diferentes na escola, conforme registros dos sujeitos 26, 27 e 104 a expressão desse sentimento. 
Para o sucesso de uma Gestão Escolar, o gestor tem que ter uma sintonia muito afinada com a comunidade, e consenquentemente que a Secretaria a qual está interligado. A autonomia conquistada por um gestor democrático é a base para o bom desempenho profissional. Vale ressaltar, que estamos caminhando para que o nosso Sistema Educacional valorize o profissional da Educação dentro de um plano de carreira que estimulante a formação continuada $(\mathrm{D} / \mathrm{G}-26)$.

Percebo que quanto mais gostamos daquilo que fazemos, quanto mais "vestimos" a camisa da escola, maior é o nosso envolvimento e maior o nosso retorno, pois para ser um educador é preciso muito amor e dedicação. Após participar do curso da Escola de Gestores, percebi como é importante o entrosamento de toda a comunidade escolar na busca de um ensino de qualidade, através de uma gestão democrática (D/G - 27).

O tempo em que estou nessa função me fez crescer profissionalmente, dando-me experiência para desenvolver cada vez melhor essa minha função como diretora. Sendo aluna da escola de gestores - UFV só tem acrescentado melhorias a minha bagagem. (D/G - 104).

Verifica-se, no entanto, que há um sentimento de expectativa de melhora no tocante às oportunidades de crescimento profissional, conforme registro dos sujeitos 33 e 63 .

Percebo que a educação caminha a passos lentos, e que colheremos os frutos a longo prazo.O primeiro passo foi dado, (capacitar os gestores) os próximos agora dependem de conseguirmos por em prática, visto que mesmo com o apoio total da secretaria municipal de educação, ainda não temos liberdade total para atuar, pois dependemos de vários fatores $(\mathrm{D} / \mathrm{G}-33)$.

Quanto a oportunidade de crescimento profissional, dentro do município é muito pouco, infelizmente ainda funciona o QI (Quem indica) isso às vezes desanima não só o gestor com os demais envolvidos no processo. Mas estamos sempre buscando lutar por nossos direitos e fazendo da melhor maneira o nosso trabalho $(\mathrm{D} / \mathrm{G}-63)$.

Os Polos Regionais Centro - Belo Horizonte e Vale do Aço Governador Valadares são aqueles em que os diretores/gestores manifestaram presença de satisfação de forma mais relevante (médias de 5,33 e 5,04, respectivamente). Nos demais polos, constatou-se uma manifestação de sentimento de indiferença, tendendo para a presença de satisfação (Tabela 3). 


\subsection{Integração social na organização}

A questão da integração social na organização é fator propiciador de satisfação, considerado positivo, na medida em que há um sentimento de comunidade na escola. Os registros dos sujeitos 54, 107, e 119 demonstram esse sentimento.

É evidente que quando seu trabalho é reconhecido e valorizado pelos seus superiores, aos quais se é submetido, o apoio moral e psicológico, financeiro, e uma relativa estabilidade quanto ao seu salário, tudo flui naturalmente propiciando um ambiente muito harmonioso (D/G 54).

De acordo com tudo isso que foi exposto, penso que só temos a ganhar se considerarmos certas coisas; o respeito mútuo, a vontade de vencer e o compromisso de participar fazendo bem feito todo o nosso trabalho. Para que o trabalho seja significativo e concreto, precisamos de que a atuação pedagógica dentro da Instituição seja pautada em parcerias com todos os segmentos escolares para que assim busquemos as alternativas e soluções para melhor atender as necessidades da escola como um todo (D/G - 107).

Percebo que a gestão escolar deverá acontecer de maneira clara, democrática, que devemos ouvir as sugestões dos outros, pois ninguém faz nada sozinho e que para obter o sucesso, é preciso ter persistência, companheirismo, ser democrático, agindo sempre com ética, nas tomadas das decisões (D/G 119).

Todos os polos apresentaram presença de satisfação, sendo o Polo Regional Triângulo - Uberlândia aquele em que os diretores/gestores manifestaram esse sentimento de forma mais relevante $(6,91)$ e o Polo Mata - Juiz de Fora, menos relevante $(5,66)$.

\subsection{Constitucionalismo ou institucionalismo}

O sentimento manifestado pelos diretores/gestores indica presença de satisfação. Esse reflexo pode ser positivo, na medida em que há sentimento de vivência democrática na escola. Observa-se, pelos registros dos sujeitos 30 e 93, a expressão desse sentimento. 
As conquistas dos últimos anos contribuíram para a tão almejada democracia: a eleição para gestores escolares, a construção do Projeto Político Pedagógico e a gestão financeira (dos recursos para manutenção da escola - PDDE). Mas, há muito que alcançar. A comunidade escolar ainda não se sente preparada para participar "integralmente" da construção dessa autonomia. O baixo capital cultural interfere na auto-estima dos pais, que se sentem incapazes de participar como protagonistas desta nova proposta de escola $(D / G-30)$.

Eu percebo que a interferência é bem acentuada. As pessoas precisam trabalhar felizes, elas precisam sentir que são valorizadas e respeitadas pelos seus superiores $(D / G-93)$.

Todos os polos apresentaram presença de satisfação, sendo o Polo Regional Triângulo - Uberlândia aquele em que os diretores/gestores manifestaram esse sentimento de forma mais relevante $(6,70)$ e o Polo Sul - Varginha, menos relevante $(5,13)$ (Tabela 3).

\subsection{Equilíbrio trabalho e vida}

A questão do equilíbrio trabalho e vida não constitui elemento propiciador de satisfação, e, sim, fator de indiferença no sentimento dos diretores. Depreende-se que o sentimento de indiferença manifestado interfere na QVT desses sujeitos, assim com reflete na gestão da escola. Esse reflexo pode ser negativo, na medida em que não se tem claro como isso se dá na escola e fora dela. Observam-se os registros dos sujeitos $4 \mathrm{e}$ 83 sobre esse sentimento.

... vivenciar um processo democrático de gestão na escola faz com que nos sintamos realizados com o compromisso político que temos enquanto educadores. Ressalto, porém que não é tão simples, na medida em que envolve a real participação da comunidade, pais, professores e funcionários necessita de tempo para encontro e reuniões. Normalmente, sobrecarrega a carga horária do gestor. No meu caso é assim. Mas não abro mão dessa participação, por ter a consciência de estar contribuindo para uma educação com mais qualidade social $(\mathrm{D} / \mathrm{G}-4)$.

Um fator que acho importante ressaltar é que não trabalhamos somente na escola, mas nosso horário fora da carga horária diária, em sua maioria, nos é solicitado, causando grande desconforto e acúmulo de funções, além de um grande desgaste emocional. Este é um fator que muito tem me incomodado, 
considerando que este é meu segundo mandato, e quarto ano na gestão de minha escola. Mas acredito que o papel do gestor é de muita valia, e um enriquecimento profissional único e riquíssimo. Uma oportunidade que nem todos os profissionais da educação possuem perfil para assumir! (D/G - 83).

De acordo com a Tabela 3, os Polos Regionais Centro - Belo Horizonte, Vale do Aço - Governador Valadares e Mata - Juiz de Fora são aqueles em que os diretores manifestaram o sentimento de indiferença, em que o último tende a mostrar presença de satisfação. Nos Polos Sul - Varginha e Norte - Montes Claros houve manifestação do sentimento de ausência de satisfação, tendendo para indiferença. Observa-se que apenas no Polo Triângulo - Uberlândia houve manifestação do sentimento de presença de satisfação.

\subsection{Relevância do trabalho}

A relevância social do trabalho é fator propiciador de satisfação e considerado positivo, na medida em que há sentimento de respeito e de orgulho. Nessa dimensão, não foi extraído nenhum fragmento textual que possa confirmar o sentimento de satisfação expresso pelos diretores/gestores. Entretanto, conforme pode ser visto na Tabela 2, os sujeitos pesquisados, em média, atribuíram o melhor escore.

A título de ilustração, pode-se inferir a relevância do trabalho mediante o registro dos depoimentos dos sujeitos 70 e 71 , nos quais são percebidos sentimentos com relação à visão que têm da escola e em relação à responsabilidade social dela para com a comunidade, refletida na preocupação de sanar problemas do processo educacional e da comunidade, além de melhorar as condições sociais e culturais e também de não prejudicar essa comunidade.

Acredito que todos os fatores internos e externos são consideráveis para construção de uma educação de qualidade, portanto, se algo não vai bem é um alerta para que possamos melhorar tornando as interferências positivas fazendo da escola um espaço autônomo, democrático e participativo (D/G 70).

Em acordo com esses pressupostos, um diretor de escola é um gestor da dinâmica social, um mobilizador e orquestrador de atores, um articulador da 
diversidade para dar-lhe unidade e consistência, na construção do ambiente educacional e promoção segura da formação de seus alunos. Para tanto, em seu trabalho, presta atenção a cada evento, circunstância e ato, como parte de um conjunto de eventos, circunstâncias e atos, considerando-os globalmente, de modo interativo e dinâmico. Implica ter uma visão da escola inserida em sua comunidade, a médio e longo prazo, com horizontes largos. (D/G - 71).

$\mathrm{Na}$ Tabela 3, nota-se que todos os polos apresentaram presença de satisfação, sendo o Polo Regional Triângulo - Uberlândia aquele em que os diretores manifestaram esse sentimento de forma mais relevante e o Polo Regional Sul - Varginha, menos relevante, com médias de 6,82 e 5,36 , respectivamente.

\section{Consideraç̃oes finais}

Com o objetivo de investigar a percepção de satisfação dos participantes do PN-EGEBP-MEC-MG em relação aos fatores pertinentes ao contexto de trabalho, bem como a interferência desses fatores na gestão escolar, tomou-se como referência a teoria desenvolvida por Herzberg e o modelo de Walton, identificando-se os sentimentos de ausência, indiferença ou de presença de satisfação, nos fatores indicativos de condições de trabalho.

A categoria Remuneração - Compensação justa e adequada aparece como aquela em que há sentimento de ausência de satisfação. Esse resultado revela a necessidade de estudos para propor ações efetivas com vistas à melhoria das condições que a contemplam, envolvendo não só a questão do salário, mas também benefícios, seguros, assistência hospitalar e a política adotada pelo Sistema de Ensino para definir essas questões.

As categorias Equilíbrio trabalho e vida e Condicões de trabalho foram as que os diretores/gestores apresentaram sentimento de indiferença. Esse cenário é preocupante e deve ser observado pela sociedade e pelas autoridades no sentido de tentar reverter esse sentimento, com o propósito de garantir educação autônoma e de qualidade, como resultado de uma gestão efetiva e participativa. Há que se pensar em ações que ratifiquem a estabilidade de horários, que garantam o equilíbrio da jornada de trabalho e exigências de carreira; que garantam a autonomia da gestão financeira da escola; que dotem de equipamentos e materiais as escolas; 
que possibilitem o uso de novas tecnologias; que garantam a segurança e a saúde, incluindo apoio psicológico e assistência à saúde dos profissionais da educação e dos seus familiares; que propiciem melhorias das condições físicas da escola; e, finalmente, que garantam as condições de integridade física e de segurança dos profissionais da educação.

Apesar, entretanto, desse cenário de demandas específicas e de conjunturas delineadas, verificou-se que os fatores que foram considerados como propiciadores de satisfação são aqueles relacionados às categorias Relevância do trabalho $(5,89)$, Integração Social na Organização $(5,74)$, Uso e desenvolvimento de capacidades $(5,32)$, Constitucionalismo ou institucionalismo $(5,31)$ e, por último, Oportunidade de crescimento e segurança $(5,02)$.

Essas categorias constituem um contraponto desse cenário, na medida em que os diretores manifestam seus sentimentos de forma satisfatória para as questões relacionadas ao respeito que a população tem pelo diretor; ao respeito que a sociedade tem para com a escola; ao respeito que a comunidade tem pelo Projeto Político-Pedagógico da escola; à responsabilidade social que a escola tem perante a comunidade; à oportunidade de ajudar outras pessoas; a importância dada às atividades que o diretor executa pela sociedade; ao orgulho e à satisfação pessoal para as atividades dele; ao orgulho e à satisfação pessoal por fazer parte da instituição; à sensação de estar contribuindo com a sociedade; à valorização e à participação que o diretor recebe do Sistema de Ensino; e as políticas públicas formuladas.

Os itens que constituem fator de satisfação entre os diretores/gestores no que tange à integração social são: o relacionamento interpessoal com os superiores e com os colegas; o clima e a cultura organizacional; a interação que há entre as pessoas na escola; o apoio dado pelos superiores e o respeito dos superiores e colegas ao diretor/gestor; a igualdade de oportunidades e o processo de comunicação; as possibilidades de lidar com situações constrangedoras; e o ambiente livre de preconceitos ou discriminações.

O Uso e desenvolvimento de capacidades verificou que a liberdade é essencial para a satisfação, uma vez que ele pode planejar, executar e avaliar; que ele tem liberdade para decidir sobre as atividades; que emprega as possibilidades para utilizar conhecimentos e habilidades nas exigências do seu trabalho; que tem possibilidades para terminar tarefas; e que lida com as informações relativas à sua função e ao seu trabalho. 
No que tange ao Constitucionalismo, mostra também que há um sentimento de satisfação relacionado à forma como se dão o tratamento e o respeito pelos direitos estabelecidos em lei; as punições estabelecidas; o respeito ao direito de defesa; a liberdade de lutar pelos direitos; o respeito e o direito de pertencer ao sindicato; a liberdade de expressão; o empenho do Sistema de Ensino para implementar sugestões; o grau de privacidade fora do trabalho; e o grau de influência de normas e rotinas no desenvolvimento dos trabalhos, percebe-se que deve haver um limiar de preocupação. Nesse sentido, há que resguardar e ratificar esses direitos.

Outra categoria que denota cuidados é aquela que trata da Oportunidade de crescimento profissional. Apesar de estar no limiar do sentimento de presença de satisfação, devem-se procurar meios para que haja possibilidades de ascensão na carreira, além de possibilidades para desenvolvimento de habilidades no trabalho que promovam o crescimento pessoal e garantam a segurança com relação ao futuro na escola.

Pode-se afirmar que os diretores/gestores da Rede Pública Municipal de Minas Gerais, participantes do PN-EGEBP-MEC, têm percepções diferenciadas para a interferência dos fatores de satisfação relacionados ao contexto de trabalho na gestão escolar. Percebem que as condições de trabalho interferem na gestão escolar. Assim, tentam mitigar essa interferência, num esforço de superação, acreditando que a função social da educação prevalece sobre as dificuldades encontradas no contexto estudado.

Com base no que foi discutido, pode-se também dizer que os resultados apresentaram consistência com a base teórica em que se respaldou a pesquisa. A teoria e o modelo analítico adaptaram-se adequadamente na identificação e na mensuração desses sentimentos e dos fatores das condições de trabalho.

Em síntese, este trabalho ratifica o entendimento de que o diretor é o principal responsável pela escola e, nesse sentido, os fatores de satisfação relacionados ao seu contexto de trabalho precisam ser conhecidos. Acredita-se que esse conhecimento possa contribuir com iniciativas e ações que ratifiquem aqueles que geram uma avaliação positiva, no sentido de garantir o cumprimento da função educativa, que é a razão de ser da escola. No entanto, para aqueles que geram avaliação desfavorável e que, consequentemente, interferem negativamente no processo da gestão 
escolar, que isso sirva de alerta para o poder público no sentido de implementar medidas para tentar reduzir esses efeitos negativos e saná-los.

O entendimento deste estudo é que o diretor é um educador, antes de ser gestor, e, assim, faz-se necessário que as políticas públicas que se destinam à educação sejam estudadas, destacando-se aquelas que dizem respeito ao contexto do trabalho, relevantemente às condições de trabalho.

Acredita-se que esta pesquisa permitiu mostrar que, apesar dos sentimentos de ausência de satisfação dos diretores/gestores para algumas situações no seu contexto de trabalho, há a prevalência do sentido de importância do trabalho realizado para a sociedade e do sentimento de integração social entre eles, os atores envolvidos e a comunidade escolar.

A título de contribuição, registram-se aqui alguns dificultadores presentes no desenvolvimento deste trabalho: a estratégia adotada para a coleta de dados, meio eletrônico, mesmo sendo eficiente, exige que o sujeito pesquisado tenha um mínimo de domínio da ferramenta; ainda, reduzido embasamento teórico do tema em instituições de ensino público.

Finalmente deve-se registrar que, no tocante à área educacional, especificamente pensando-se em QVT, sugere-se uma categoria diferente - seria a nona - que poderia ser acrescentada às oito sugeridas por Walton. É o comprometimento com o fazer do homem enquanto agente de transformação - com a família e com a comunidade como um todo, diferentemente das organizações industriais, tendo em vista que seu produto é a formação do ser humano enquanto sujeito social. 


\section{Referências}

BARDIN, L. Análise de conteúdo. Trad. Luís Antero Reto e Augusto Pinheiro. Lisboa: Edições 70, 1977.

CRITELLI, D. O trabalho e o sentido da vida. Folha de S.Paulo, São Paulo, 2 mar. 2006. [Outras Ideias].

CUNHA, N. R. S.; MACHADO, R. C. P.; MOURA, L. R. C.; MOURA, L. E.L. Qualidade de vida no trabalho: a mensuração da percepção dos servidores em uma organização hospitalar. In: ENCONTRO DE ADMINISTRAÇÃO PÚBLICA E GOVERNANÇA DA ANPAD - Associação Nacional de Pós-Graduação e Pesquisa em Administração. Salvador, BA. Anais..., 2008.

DAVIS, L. E. The design of jobs. Industrial Relations, October, 1966.

DIMENSTEIN, G. Você seria professor de escola pública? Folha de S.Paulo, São Paulo, 1 jun. 2009.

HACKMAN, J. R.; OLDHAM, G. R. Development of the job diagnostic survey. Journal of Applied Psychology, [S.1.], v. 60, n. 2, p. 159-170, 1975.

DORNBUSCH, S.M.; GLASGOW, K.L.; LIN, I.C. The social structure of schooling. American Review Psychologist, [S.1.], v. 47, p. 401-429, 1996.

HAIR, JR. J. F. et al. Fundamentos de métodos de pesquisa em administração. Trad. Lene Belon Ribeiro. Porto Alegre: Bookman, 2005.

HERZBERG, F. The motivation to work. 2 ed. New York: John Wiley \& Sons, Inc., 1967.

MACHADO, C. L. B. Motivação, qualidade de vida e participação no trabalho. 94p. Dissertação (Mestrado em Engenharia de Produção) - Universidade Federal de Santa Catarina, Florianópolis, 2002.

MELLO, M. S. O. Qualidade de vida no trabalho e motivação. Agathos: Revista Científica da Assevim, [S.1.], n. 2, v. 2, 2006.

MINTZBERG, H. Criando organizações eficažes: estruturas em cinco configurações. São Paulo: Atlas, 1995. 304p.

OLIVEIRA, R. C. M. A configuração da QVT no contexto de trabalho dos detetives da Polícia Civil Metropolitana de Belo Horizonte. 157p. Dissertação (Mestrado em Administração) Departamento de Ciências Administrativas, Universidade Federal de Minas Gerais, Belo Horizonte, 2001.

NADLER, D. A., LAWLER, E. E. Quality of work life. Perspectives and directions. Organization Dynamics. Winter, 1983.

PARO, V. H. Capítulo IV - Administração escolar e transformação social. In: PARO, V. H. Administração escolar: introdução crítica. 11 ed. São Paulo: Cortez, 2002. p. 123-135. TORRES, A.; GARSKE, L. M. N. Diretores de escola: o desacerto com a democracia. Em aberto: gestão escolar e formação de gestores, Brasília, v. 17, n. 12, p. 60-70, 2000.

SÁ, M. A. D.; HONÓRIO, J. B.; OLIVEIRA, R. C. R.; VIANA, K. M. P. Qualidade de vida no trabalho docente - uma questão de prazer! In: XXXI ENCONTRO DA ANPAD - Associação Nacional de Pós-Graduação e Pesquisa em Administração. Rio de Janeiro. Anais..., 2007.

VELOSO, H. M.; BOSQUETTI, M. A.; FRANÇA, A. C. L. A concepção gerencial dos programas de qualidade de vida no trabalho (QVT) no setor elétrico brasileira. In: SEMEAD. Anais..., 2005. 
WALTON, R. Quality if working life: what is it? Sloan Management Review, Cambridge, v. 15, n. 1, p. 11-21, 1973.

WESTLEY, W. A. Problems and solutions in the quality of working life. Human Relations, v. 32, n. 2, p. 11-123, 1979.

Recebido: 09/09/2010

Aprovado: 19/04/2011

Contato:

Universidade Federal de Viçosa

Departamento de Administração

Avenida Peter Henry Rolfs, s/n

Campus Universitário

CEP 36570000

Viçosa, MG

Brasil 